\title{
Febrile convulsions in a national cohort followed up from birth. II-Medical history and intellectual ability at 5 years of age
}

\author{
C M VERITY, N R BUTLER, JEAN GOLDING
}

\begin{abstract}
Three hundred and three children with febrile convulsions were identified in a national birth cohort of 13135 children followed up from birth to the age of 5 years. Breech delivery $(p<0.05)$ was the only significantly associated prenatal or perinatal factor. There were no associations with socioeconomic factors.

Excluding the 13 known to be neurologically abnormal before their first febrile convulsion, children who had had a febrile convulsion did not differ at age 5 from their peers who had not had febrile convulsions in their behaviour, height, head circumference, or performance in simple intellectual tests.
\end{abstract}

\section{Introduction}

Although febrile convulsions are relatively common, considerable confusion remains about whether the seizures in themselves have a deleterious effect on the subsequent development of the child. Theoretically, at least, a convulsion can result in cerebral anoxia with the death of brain cells and consequent loss of intellectual and motor ability.

In 1942 Thom published the results of a community based study of children who had had "infantile convulsions." $1 \mathrm{He}$ reported that $12 \%$ of these children were mentally defective (Intelligence Quotient (IQ) $<75$ ) and a further $13^{\circ}{ }_{0}$ retarded (IQ 75-90), concluding that "infantile convulsions do tend to increase materially the risk of epilepsy and mental deficiency in later life." The study may be criticised: the children were part of a selected group; their neurological state before the convulsions was not taken into account and the infantile convulsions were of mixed aetiology and type. These criticisms apply to many subsequent follow up studies of children who have had febrile convulsions and may explain the wide variation in the reported intellectual outcome in such children.

The incidence of mental retardation in children who have had febrile convulsions was found to be $22^{\circ}{ }_{0}$ by Lennox, ${ }^{2} 13.4^{\circ}{ }_{0}$ by Aicardi and Chevrie, ${ }^{3}$ and $8^{\circ}{ }_{0}$ by Wallace and Cull. ${ }^{4}$ They all studied children who had been seen as inpatients or outpatients in hospital. Population based studies might well be expected to reach different conclusions. Indeed, in 1978 Ellenberg and Nelson in the United States reported that in a "large prospectively-defined population not selected for medical care" febrile convulsions were not associated with a reduction in IQ or early academic performance as judged by comparison of affected children with their siblings. ${ }^{5}$

Department of Child Health, University of Bristol, Bristel BS1 5QD C M VERITY, MRCP, DCH, lecturer

N R BUTLER, FRCP, FRCOG, professor

JEAN GOLDING, MA, PHD, senior lecture

Correspondence to: Dr C Verity, Department of Child Health, Royal Hospital for Sick Children, Bristol BS2 8BJ.
Here we present data concerning 303 children with a history of febrile convulsions from a nationally representative British population of 13135 children.

\section{Subjects and methods}

Children who had had febrile convulsions were divided into groups according to whether their convulsions were complex or simple or whether they had had any prior neurological abnormality. Definitions were as in the preceding paper except that children who had had one or more complex convulsions at any time were said to have complex convulsions $(n=67)$ and children who had had one or more convulsions none of which was complex were said to have simple convulsions $(n=123)$. Thirteen children were known to have had a neurological abnormality that preceded the first convulsion; these abnormalities are listed in the previous paper.

In addition, the children with complex convulsions were subdivided for various analyses according to whether they had had a convulsion that lasted for at least 60 minutes $(n=10)$ or unilateral convulsions $(n=10)$. These two groups overlapped, but the aim was to see whether either factor was important when assessing the later development of the child.

TESTS OF PERFORMANCE AT 5 YEARS OLD

The children's intellectual ability was assessed at five years using relatively simple tests that could be administered by the health visitor at the child's home: the copying designs test, the draw a man test, the English picture vocabulary test (survey version), the "profile" test, and a reading test. ${ }^{6}$

On analysing the data we found that the copying designs and the English picture vocabulary tests yielded the most useful information; the results from the three other tests have been omitted from this paper. $^{6}$

\section{Results}

\section{PERINATAL FACTORS}

Birth weight had been recorded for 300 of the 303 children with febrile convulsions. Follow up at five years showed that $30\left(3.4^{\prime \prime}{ }_{0}\right)$ of the 883 infants weighing $2500 \mathrm{~g}$ or less at birth had febrile convulsions compared with $270\left(2.3^{\circ}\right)$ of the 11872 who had weighed more than $2500 \mathrm{~g}\left(\%^{2}\right.$ with Yates's correction $\left.=4.0 ; \mathrm{p}<0.05\right)$. When, however, children with a prior neurological abnormality were omitted (five of low birth weight, eight others) the difference in proportions $\left(28^{\prime \prime}\right.$, $\left.v 2 \cdot 2^{\prime \prime}{ }_{11}\right)$ was no longer significant $\left(\%^{2}\right.$ with Yates's correction $=1 \cdot 2$; NS).

History of abnormalities in pregnancy did not differ between children who had had febrile convulsions and those who had not, but there were differences in the mode of delivery. In all, $17\left(3.8^{\circ} \circ\right)$ of the 450 children delivered by the breech had had febrile convulsions compared with $262\left(2 \cdot 2^{\circ}{ }_{10}\right)$ of those delivered by the vertex ( $\%^{2}$ with Yates's correction $=4.4 ; p<0.05)$. This result was not due to the children who had had a prior neurological defect.

\section{SOCIAL BACKGROUND}

Prevalence of a history of febrile convulsions did not vary significantly with social class: the proportions varied from $2 \cdot 3 \%(19 / 843)$ 
of social class I, $2 \cdot 5 \%(61 / 2405)$ of social class II, $2 \cdot 2 \%$ (148/6795) of social class III, $\left(2 \cdot 2^{\circ} \%(35 / 1620)\right.$ of social class IV, to $2 \cdot 8^{\circ} \%(17 / 605)$ of social class $\mathrm{V}$. In addition, the prevalence of febrile convulsions did not vary significantly with number of children in the household, educational qualifications of parents, type of housing, or region of the country.

\section{MEDICAL HISTORY}

The information collected on all the children examined at the age of 5 was used to calculate the proportion of children with febrile convulsions who had other signs or symptoms. There were no significant associations with many factors including past eczema, hay fever, asthma or wheezing, accidental injuries, bronchitis, and squints or defective vision. Children with a history of discharging ears, frequent sore throats, or pneumonia were, however, significantly more likely also to have a history of febrile convulsions (table I). In consequence of the association with upper respiratory tract infection children with febrile convulsions were also found more often among those who had undergone a tonsillectomy.

\section{OUTCOME}

Our findings show that children with febrile convulsions did not differ from the rest of the population in any detectable aspect of their

TABLE I-Medical history of children with history of febrile convulsions: Data are for significant associations alone. Figures indicate numbers of children with convulsions together with proportion of all children in the cohort in parentheses

\begin{tabular}{|c|c|c|c|c|c|}
\hline & & \multirow{2}{*}{$\begin{array}{l}\text { No of } \\
\text { children } \\
\text { in } \\
\text { chort }\end{array}$} & \multicolumn{3}{|c|}{ Children with febrile convulsions } \\
\hline & & & Boys & Girls & Total \\
\hline $\begin{array}{l}\text { Ear discharge } \\
\text { (pus not wax) }\end{array}$ & $\left\{\begin{array}{l}\text { Yes } \\
\text { No }\end{array}\right.$ & $\begin{array}{rr}1451 \\
11 & 140\end{array}$ & $\begin{array}{r}33(4 \cdot 2) \\
114(2 \cdot 0)^{*}\end{array}$ & $\begin{array}{r}24(3 \cdot 6) \\
* * * 109(2 \cdot 0)^{* *}\end{array}$ & $\begin{array}{r}57(3.9) \\
223(2 \cdot 0)^{* * * * *}\end{array}$ \\
\hline Frequent sore throats & $\left\{\begin{array}{l}\text { Yes } \\
\text { No }\end{array}\right.$ & $\begin{array}{r}2623 \\
10076\end{array}$ & $\begin{array}{l}71(5 \cdot 0) \\
84(1 \cdot 6)^{*}\end{array}$ & $* * * \begin{array}{l}48(4 \cdot 0) \\
89(1 \cdot 8) * * * *\end{array}$ & $\begin{array}{l}119(4 \cdot 5) \\
173(1 \cdot 7)^{* * * *}\end{array}$ \\
\hline Pneumonia & $\left\{\begin{array}{l}\text { Yes } \\
\text { No }\end{array}\right.$ & $\begin{array}{r}205 \\
12370\end{array}$ & $\begin{array}{r}3(2 \cdot 6) \\
144(2 \cdot 3)+\end{array}$ & $\begin{array}{c}7(7 \cdot 8) \\
127(2 \cdot 1)^{* * *}\end{array}$ & $\begin{array}{c}10(4 \cdot 9) \\
271(2 \cdot 2)^{*}\end{array}$ \\
\hline Tonsillectomy & $\left\{\begin{array}{l}\text { Yes } \\
\text { No }\end{array}\right.$ & $\begin{array}{r}281 \\
12473\end{array}$ & $\begin{array}{r}13(7 \cdot 8) \\
138(2 \cdot 2)\end{array}$ & $\begin{array}{c}5(4 \cdot 3) \\
* * * * 134(2 \cdot 2)+\end{array}$ & $\begin{array}{c}18(6 \cdot 4) \\
273(2 \cdot 2)^{* * * * *}\end{array}$ \\
\hline
\end{tabular}

p Values: $*<0.05 ; * *<0.01 ; * * *<0.001 ; * * * * 0.0001$

+ Not significant.

TABLE II-Number $(\%)$ of children with various types of febrile convulsion to have additional problems

\begin{tabular}{|c|c|c|c|c|c|}
\hline & $\begin{array}{c}\text { Simple } \\
\text { con- } \\
\text { vulsions }\end{array}$ & $\begin{array}{l}\text { Complex } \\
\text { con- } \\
\text { vulsions }\end{array}$ & $\begin{array}{l}\text { Simple } \\
\text { or } \\
\text { complex } \\
\text { con- } \\
\text { vulsions }\end{array}$ & $\begin{array}{c}\text { No } \\
\text { febrile } \\
\text { con- } \\
\text { vulsions }\end{array}$ & $\begin{array}{c}\text { Con- } \\
\text { vulsions } \\
\text { plus } \\
\text { neuro- } \\
\text { logical } \\
\text { ab- } \\
\text { normality }\end{array}$ \\
\hline $\begin{array}{l}\text { Sleeping problem } \\
\text { Hearing difficulty } \\
\text { Speech problem } \\
\text { Speech therapy }\end{array}$ & $\begin{array}{l}71(32 \cdot 3) \\
26(12 \cdot 2) \\
37(17 \cdot 9) \\
14(7 \cdot 0)\end{array}$ & $\begin{array}{rr}20 & (29 \cdot 9) \\
8 & (12 \cdot 3) \\
5 & (8 \cdot 1) \\
2 & (3 \cdot 2)\end{array}$ & $\begin{array}{l}91(31 \cdot 7)^{* *} \\
34(12 \cdot 2)^{*} \\
42(15 \cdot 6)^{*} \\
16(6 \cdot 1)^{+}\end{array}$ & $\begin{array}{rl}3 & 173(24 \cdot 9) \\
1 & 018(8 \cdot 3) \\
1 & 317(11 \cdot 2) \\
496(4 \cdot 2)\end{array}$ & $\begin{array}{l}7(53 \cdot 8) \\
3(25 \cdot 0) \\
4(50 \cdot 0) \\
5(45 \cdot 5)\end{array}$ \\
\hline
\end{tabular}

Significance denotes test of all children with simple or complex febrile convulsions

against those with no febrile convulsions.

p Values: $* 0.05$
+ Not significant. social background. The only associated medical factor appeared to be infections of the upper respiratory tract. When the children with prior neurological abnormality were excluded there was no association with birth weight and only a slight association with breech delivery. In discussion of measures of outcome breech delivery is therefore the only factor that needs to be taken into consideration.

\section{OUTCOME FOR BEHAVIOUR, HEARING, AND SPEECH}

The children with a history of febrile convulsions differed in their behaviour at 5 years from the children with no such history in only one respect: they were more likely to have sleeping problems (table II).

As far as the type of sleeping problem was concerned, there was no difference in the number of children who walked in their sleep or woke early in the morning, but an excess of children with a history of febrile convulsions had nightmares or night terrors $\left(6.6{ }^{\circ} v 4.9 \%\right)$ or difficulty getting off to sleep $(10.8 \%$ v $8.8 \%)$ or woke during the night $(12.2 \%$ $v 10 \cdot 8 \%$ ).

More children with a history of febrile convulsions had been suspected of having hearing problems, but this was not unexpected as they were also more likely to have a history suggestive of otitis media.

Children with febrile convulsions were also more likely to have a speech problem. Curiously, it was children who had had simple rather than complex febrile convulsions that were affected. Of the 42 children affected, 11 no longer had the problem, and in only one was it said to be severe. Although children with febrile convulsions were more likely to have had speech therapy, numbers were too small to be significant. There was no significant association with stammering or stuttering.

\section{PHYSICAL AND INTELLECTUAL ASSESSMENT}

Children with prior neurological abnormalities, as expected, performed significantly worse in the intellectual tests and were slightly shorter than the rest of the population. Their mean head circumference was similar to that of the other children but had a large standard error, reflecting the presence of children with both hydrocephalus and microcephaly in this group.

Children who had had simple or complex febrile convulsions did not differ significantly from the rest of the population in regard to their mean height, head circumference, or performance in the two intellectual tests (table III).

\section{SEX DIFFERENCES}

Table IV shows data on outcome for each sex. Significant differences in sleeping problems and hearing difficulty $(p<0.01)$ appeared to be confined to girls rather than boys. The proportion of children with speech problems, however, was higher in both sexes of children with a history of febrile convulsions, but there were no sex differences in other outcomes.

\section{ANALYSIS OF VARIANCE}

To see whether differences in measures of outcome associated with febrile convulsions were merely a consequence of the association with breech delivery analyses of variance were carried out with the three independent variables: sex, method of delivery (breech, other), and history of febrile convulsions (present, absent) using all the children in the cohort with the exception of those with a prior neuro-

TABLE III-Mean (SE) height, head circumference, and intellectual ability in children according to type of febrile convulsion

\begin{tabular}{|c|c|c|c|c|c|}
\hline & Simple convulsion & Complex convulsion & $\begin{array}{l}\text { Simple or complex } \\
\text { convulsion }\end{array}$ & No convulsions & $\begin{array}{l}\text { Convulsion plus } \\
\text { neurological } \\
\text { abnormality }\end{array}$ \\
\hline Height of child & $108.69(0.33)$ & $109.69(0.55)$ & \multirow{4}{*}{$\begin{array}{c}108.93(0.29) \\
(\mathrm{n}=282) \\
51.94(0.11) \\
(\mathrm{n}=284) \\
0.033(0.06) \\
(\mathrm{n}=273) \\
4.54(0.12) \\
(\mathrm{n}=290)\end{array}$} & $108.74(0.05)$ & \multirow{4}{*}{$\begin{array}{c}106.75(1.94) \\
(\mathrm{n}=12) \\
51.83(0.74) \\
(\mathrm{n}=12) \\
-1.121(0.365) \\
(\mathrm{n}=9) \\
1.62(0.84) \\
(\mathrm{n}=13)\end{array}$} \\
\hline Head circumference & $\begin{array}{l}(n=215) \\
51 \cdot 89(0 \cdot 13)\end{array}$ & $\begin{array}{c}(n=67) \\
52.09(0.24)\end{array}$ & & $51.77(0.12)$ & \\
\hline English picture vocabulary test score & $\begin{array}{c}(n=217) \\
0.060(0.07)\end{array}$ & $\begin{array}{c}(n=67) \\
-0.060(0.12)\end{array}$ & & $0.001(0.009)$ & \\
\hline Copying designs score & $\begin{array}{l}(n=211) \\
4.59(0.14) \\
(n=223)\end{array}$ & $\begin{array}{c}(n=62) \\
4.37(0.24) \\
(n=67)\end{array}$ & & $4.67(0.02)$ & \\
\hline
\end{tabular}


TABLE IV-Differences in outcome between the sexes. Children with a prior neurological abnormality omitted

\begin{tabular}{|c|c|c|c|c|}
\hline & \multicolumn{2}{|c|}{ Boys } & \multicolumn{2}{|c|}{ Girls } \\
\hline & History of convulsions & No history of convulsions & History of convulsions & No history of convulsions \\
\hline $\begin{array}{l}\text { No (") with sleeping problem } \\
\text { No (") with hearing difficulty } \\
\text { No (") with speech problem } \\
\text { Mean (SE) height (cm) } \\
\text { Mean (SE) head circumference (cm) } \\
\text { Mean (SE) English picture vocabulary test score } \\
\text { Mean (SE) copying designs score }\end{array}$ & $\begin{array}{c}43(27 \cdot 7) \\
16(11 \cdot 0) \\
26(18 \cdot 2) \\
109 \cdot 28(0 \cdot 43) \\
(n=152) \\
52 \cdot 57(0 \cdot 14) \\
(n=152) \\
0 \cdot 189(0 \cdot 08) \\
(n=147) \\
4 \cdot 590(0 \cdot 16) \\
(n=156)\end{array}$ & $\begin{array}{c}1605(24 \cdot 4) \\
586(9 \cdot 2) \\
828(13 \cdot 8) \\
109 \cdot 11(0 \cdot 06) \\
(n=6516) \\
52 \cdot 28(0 \cdot 02) \\
(n=6487) \\
0 \cdot 103(0.013) \\
(n=6191) \\
4 \cdot 680(0 \cdot 03) \\
(n=6647)\end{array}$ & $\begin{array}{c}48(36 \cdot 4) \\
18(13.6) \\
16(12.7) \\
108 \cdot 52(0.47) \\
(\mathrm{n}=130) \\
51 \cdot 20(0 \cdot 17) \\
(\mathrm{n}=132) \\
-0 \cdot 150(0 \cdot 09) \\
(\mathrm{n}=126) \\
4 \cdot 485(0.21) \\
(\mathrm{n}=134)\end{array}$ & $\begin{array}{c}1568(25 \cdot 5) * \\
432(7 \cdot 2)^{*} \\
489(8 \cdot 5) \\
108 \cdot 34(0.07) \\
(n=6082) \\
51 \cdot 21(0 \cdot 02) \\
(n=6061) \\
-0 \cdot 109(0.01) \\
(n=5761) \\
4 \cdot 659(0.03) \\
(n=6185)\end{array}$ \\
\hline
\end{tabular}

Statistical differences are between groups with and without a history of febrile convulsions.

p $<0.01$.

\begin{tabular}{|c|c|c|c|}
\hline Dependent variable & Sex effect & Delivery effect & Febrile convulsions effect \\
\hline $\begin{array}{l}\text { Head circumference } \\
\text { Height } \\
\text { English picture vocabulary test score } \\
\text { Copying designs score }\end{array}$ & $\begin{aligned} & 1081^{* * *}\left(1081^{* * *}\right)\left(66^{* * *}(66)\right. \\
& 135^{* * *}\left(134^{* * *}\right) \\
& 0 \cdot 2(0 \cdot 2)\end{aligned}$ & $\begin{array}{c}1 \cdot 8(1 \cdot 8) \\
7 \cdot 3^{* *}\left(7 \cdot 1^{* *}\right) \\
5 \cdot 2^{*}\left(5 \cdot 3^{*}\right) \\
12 \cdot 5^{* *}\left(12 \cdot 6^{* *}\right)\end{array}$ & $\begin{array}{l}2 \cdot 2(1.6) \\
0.5(1.0) \\
0 \cdot 1(0.1) \\
0.7(0.9)\end{array}$ \\
\hline $\mathrm{df}$ & $1(1)$ & $1(1)$ & $1(2)$ \\
\hline
\end{tabular}

logical abnormality (table V). In no case was there any evidence of an association between febrile convulsions and adverse outcome or of any significant interactions between febrile convulsions and sex or febrile convulsions and type of delivery.

\section{UNILATERAL CONVULSIONS}

Ten children had had unilateral convulsions, in six of whom the episode had lasted for at least an hour. All had been delivered spontaneously by the vertex, but three had been of low birth weight. Six were girls. The mean result achieved by these children in the English picture vocabulary test was -0.292 (SE 0.452) compared with $0.001(0.009)$ for the rest of the population $(p=0.4)$; the results for the copying designs test were $4 \cdot 100(0.640)$ and $4.727(0.017)(p=0 \cdot 3)$. Thus, although these children performed less well in the tests, the differences were no more than might be expected to occur by chance.

\section{CONVULSIONS LASTING MORE THAN AN HOUR}

Ten children had had a febrile convulsion lasting at least one hour. Seven of these were girls, and six $\left(60^{\circ}\right)$ had had their first febrile convulsion in the first year of life. Not surprisingly, as there was a large overlap with the children who had had unilateral convulsions, there was a deficit in the test results for this group (English piciure vocabulary tests score $-0.253(0.360)$ compared with $0.001(0.009)$ $(\mathrm{p}=0.4)$ for the whole population of 5 year olds; copying designs test score $3.80(0.727)$ compared with $4.727(0.017)(p=0.13)$ for the whole population)

\section{Discussion}

\section{DEFINITIONS}

The way in which febrile convulsions are defined inevitably affects the conclusions drawn by a particular study. In 1947 Livingstone et al pointed out that many previous authors had included in their analyses all types of childhood convulsions and reported the results of a special study of children "whose first convulsion was associated with an acute febrile illness." " Lennox defined a febrile convulsion as severe if it or the following coma lasted an hour or more or if it started in, or included chiefly, one arm or leg or one side of the body. ${ }^{2}$ Fowler reported on five children who presented at the beginning of a febrile illness with convulsions lasting from one to six hours after which they all remained unconscious. ${ }^{\circ}$ Four died, and the fifth remained in coma. These five patients could not be regarded as having had "simple febrile convulsions" as defined by Livingstone in $1958 .{ }^{9}$ $\mathrm{He}$ applied this diagnosis to patients under 6 years of age who had (1) short generalised seizures, averaging one to five minutes, which occurred soon after a rise in temperature associated with an extracranial infection and (2) a normal electroencephalogram after being without fever for at least one week.

Wallace defined a febrile convulsion as "any convulsive episode occurring in association with any feverish illness" and further defined the convulsion as complicated if it continued for more than half an hour, had unilateral features, or was repeated in the same illness. ${ }^{10}$ Lennox-Buchtal reported on the definition used in a large symposium on febrile convulsions-any child who had a convulsion with a rectal temperature of $38^{\circ} \mathrm{C}$ or more should be described as "susceptible to convulsions with fever" whether or not that child previously or subsequently had afebrile seizures or sustained a convulsion that was short or long, generalised or unilateral. ${ }^{11}$

The definition of febrile convulsion used in the present study was that published after the Consensus Development Conference held at the National Institutes of Health in 1980: "An event in infancy or childhood, usually occurring between 3 months and 5 years of age, associated with fever but without evidence of intracranial infection or defined cause." 12 It is important to emphasise that this definition excludes all infants with convulsions associated with meningitis. Our definition of complex febrile convulsions was that used by Ellenberg and Nelson in 1978: febrile convulsions lasting more than 15 minutes, with focal features, or multiple (more than one convulsion in each episode of fever).

\section{RELATION BETWEEN PERINATAL EVENTS AND FEBRILE CONVULSIONS}

There is disagreement as to whether prenatal or perinatal events are associated with predisposition to febrile convulsions. For example, in Millichap's series of 95 patients evidence suggesting prenatal injury or birth injury was present in $21 \%$ and $20 \%$ of patients, respectively. ${ }^{13} \mathrm{He}$ also reviewed 19 series of patients and 17 publications between 1933 and 1963 and found evidence of possible brain injury caused by trauma or 
anoxia in $17 \%$. Heijbel et al found that prenatal and perinatal complications were significantly more common in children with febrile convulsions than in a randomly selected group of controls; numbers were too small to analyse the individual importance of different types of complication. ${ }^{14}$

In an analysis of discordant pairs of twins SchiottzChristensen and Bruhn failed to find a correlation between birth history and intellectual development in those twins who had sustained febrile convulsions. ${ }^{15}$ Wallace suggested in 1972 that in up to $61^{\prime \prime}$ "of children in whom a first convulsion occurs with febrile illness an abnormal pregnancy or perinatal history may predispose them to the attack, ${ }^{16}$ but the incidence of forceps and breech delivery considered separately or together was marginally higher in the siblings of the patients studied than in the patients themselves.

The present data show that little distinguished the children with febrile convulsions from the rest of the study population but that a significantly greater proportion had been delivered by the breech.

In all these studies interpretation depends on the validity of the controls used and the problems of recall bias. These problems are overcome in longitudinal studies such as the National Child Development Study ${ }^{1}$ and the Californian Kaiser Permanante Study. ${ }^{1 \times}$ Neither of these found any significant association with perinatal events. Our own study also gave predominantly negative results, with only breech delivery being significantly associated. As the association was significant only at the $5^{\circ}{ }_{0}$ level and appeared only when over 20 prenatal and perinatal factors had been determined the association probably arose by chance alone.

\section{BEHAVIOUR}

An extensive series of questions about behaviour' failed to show any significant differences between patients with febrile convulsions and the rest of the population in our longitudinal study. This is in contrast with some but not all published findings. Friderichsen and Melchior, for example, found behavioural disorders in $4^{\circ}{ }^{\circ}$ of their patients, ${ }^{19}$ but Millichap reported behaviour disorders in $35^{\circ}{ }^{\circ}$ in his study. ${ }^{13}$ Schiottz-Christensen and Bruhn did not find any evidence that febrile convulsions influenced later behaviour in the discordant pairs of twins that they studied, but Wallace reported seriously disturbed behaviour in 27 of 100 children in her series. ${ }^{20}$ Twenty three per cent of the children became known to the local educational psychologists.

\section{INTELLECTUAL PROGRESS}

This study failed to show a significant difference between either the patients with simple convulsions or those with complex febrile convulsions and the rest of the study population for either the English picture vocabulary test or the copying designs score.

Schiottz-Christensen and Bruhn in a careful study of 14 monozygous pairs of twins showed significant intellectual impairment in the twins who had had febrile convulsions, although the deficits were small. ${ }^{15}$ They were not, however, able to conclude that the febrile convulsions in themselves had caused cerebral dysfunction. Wallace reported that in $38\left(28^{\circ}{ }_{0}\right)$ of 134 children admitted to hospital because of febrile convulsions detailed developmental history and physical examination indicated that a neurological disorder had preceded the convulsion. ${ }^{21}$ Subsequent psychological assessment of 102 of these children showed a mean full scale IQ of 100.5 on the Wechsler intelligence scale. Eight children had an IQ of less than 70. Seven of these children had evidence of suboptimal development before their first fit. Despite satisfactory general intelligence, both the draw a person and Bender tests showed that many children had poor visuomotor skills. Intellect in boys did not seem to be greatly affected by repeated fits, but girls appeared to suffer damage from the convulsions themselves, especially when the initial fit was unilateral.

Aldridge-Smith and Wallace reported that after an initial febrile convulsion subsequent attacks were more likely to be detrimental to overall intellectual development than continuous prophylactic treatment with either phenobarbitone or sodium valproate. ${ }^{22}$ Wallace recently reviewed the published data on intellectual development after febrile convulsions. ${ }^{20}$

Ellenberg and Nelson selected 431 of the 1706 children with febrile convulsions in the Collaborative Perinatal Project. ${ }^{5}$ These children were compared with siblings in the study who had not had febrile convulsions and who acted as controls for intellectual testing at 7 years of age. The mean full scale IQ on the Wechsler intelligence scale for children who had experienced febrile convulsions was 93.0 , which was not significantly different from that for the controls. As in our study, children who were suspected of being abnormal, or were abnormal, before their first seizures scored significantly lower than their normal siblings. No significant differences were found between the mean IQ of children with pure (simple) convulsions and that of children with complex febrile convulsions. Children with febrile convulsions lasting longer than 30 minutes did not have significantly different IQs. A tendency for the mean differences between index cases and controls to increase as numbers of seizures increased did not reach significance, and this trend disappeared when only previously normal children were considered.

Ross et al reported on the progress of 366 children who developed febrile convulsions out of the cohort followed up by the National Child Development Study. ${ }^{1}$ In the 346 children with febrile convulsions who did not develop subsequent seizures without fever attainment at school at 11 years was similar to that of the rest of the cohort.

Thus two large population based studies, one in America and the other in the United Kingdom, agreed with the present data in finding little difference between children who had had febrile convulsions and the rest of the study population in terms of the tests of performance used. Where authors have included children with prior neurological abnormality or considered only those children referred to a specialist centre the results have tended to be less favourable.

Our data illustrate the overall value of longitudinal population based studies in producing results that eliminate such biases. We have looked at fairly crude measures of intellectual progress at the age of 5 . We shall be analysing the information collected on these children at the age of 10 to see whether any subtle adverse effects on various aspects of intellectual development or motor coordination can be detected.

The 1970 cohort study was possible because of the active cooperation of local midwives and health visitors in collecting information and the funding of various bodies including the Medical Research Council, the Department of Health and Social Security, and the Gertrude H Sergievsky Center of Columbia University, New York. JG was in receipt of a Wellcome Trust senior lectureship. For this study we also thank Yasmin Iles for her secretarial skills; the general practitioners, medical records officers, and clinicians who responded to our plea for further information; Mr Patrick West who started the research project; but especially the cohort children themselves and their parents.

\section{References}

1 Thom DA. Convulsions of early life and their relation to the chronic convulsive disorders and mental defect. Am $\mathcal{F}$ Psychiatry 1942;98:574-80.

2 Lennox MA. Febrile convulsions in childhood. A clinical and electroencephalographic study. Am $\mathcal{F}$ Dis Child 1949;78:868-82. retardation. In: Brazier $\mathrm{MAB}$. Coceani $\mathrm{F}$, eds Brain dysfunction in infantile fetardation. In: Brazier MAB, Coceani F, eds. Brain dysfunc Wallace SJ, Cull AM. Long-term psychological outlook for children whose first fit occurs with fever. Dev Med Child Neurol 1979;21:28-40.

5 Ellenberg JH, Nelson KB. Febrile seizures and later intellectual performance. Arch Neurol 1978;35:17-21.

6 Osborn AF, Butler NR, Morris AC. The social life of Britain's five-year-olds. London: Routledge and Kegan Paul, 1984.

7 Livingstone S, Bridge EM, Kajdi L. Febrile convulsions: a clinical study with special reference to heredity and prognosis. $\mathcal{F}$ Pediatr $1947 ; 31: 509-12$.
Fowler M. Brain damage after febrile convulsions. Arch Dis Child 1957;32:67-76. 


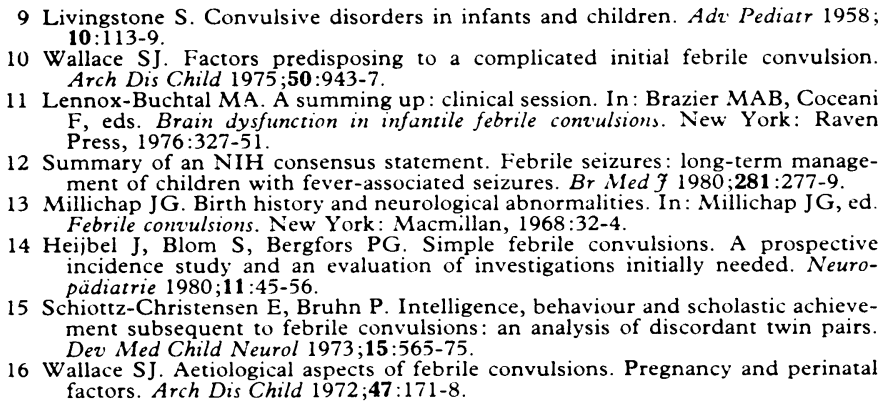

15 Schiottz-Christensen E, Bruhn P. Intelligence, behaviour and scholastic achievement subsequent to febrile convulsions: an analysis of discordant twin pairs. ment subsequent to febrile convulsions:

16 Wallace SJ. Aetiological aspects of febrile convulsions. Pregnancy and perinatal factors. Arch Dis Child 1972;47:171-8.

17 Ross EM, Peckham CS, W'est PB, Butler NR. Epilepsy in childhood: findings from the National Child Development Study. BrMed $\mathcal{F} 1980 ; 280: 207-10$.

Van den Berg BJ, Yerushalmy $J$. Studies on convulsive disorders in young children. I. Incidence of febrile and nonfebrile convulsions by age and other factors. Pediatr Res $1969 ; 3: 298-304$.

19 Friderichsen C, Melchior J. Febrile convulsions in children, their frequencr

20 Wallace S J. Febrile convulsions: their significance for later intellectual development and behaviour. $\mathcal{F}$ Child Psychol Psychiatry $1984 ; 25: 15-2$ allace $S$ J. Neurological and intellectual deficits: convulsions with fever viewed as acute indications of life-long developmental defects. In: Brazier M.AB, Coceani F, eds. Brain dysfun

22 Aldridge-Smith J, Wallace SJ Febrile convulsions: intellectual progress in relation to anti-convulsant therapy and to recurrence of fits. Arch Dis Child 1982;57:104-7.

(Accepted 28 fanuary 1985)

\title{
Effect of enterocoated cholestyramine on bowel habit after ileal resection: a double blind crossover study
}

\author{
OLI JACOBSEN, LISELOTTE HØJGAARD, ELLINOR HYLANDER MØLLER, \\ TORBEN O WIELANDT, MARGRETHE THALE, STIG JARNUM, EINAR KRAG
}

\begin{abstract}
Ileal resection causes malabsorption of bile acid; the increased load of bile acids in the colon induces increased secretion of salt and water and hence diarrhoea. A study was carried out to test the effect of an enterocoated cholestyramine tablet designed to disintegrate in the colon and sequester the bile acids there, thereby minimising diarrhoea induced by bile acids while having no effect on malabsorption of bile acid and jejunal fat absorption.
\end{abstract}

The study comprised 14 patients who had undergone ileal resection of $40-150 \mathrm{~cm}$ for Crohn's disease. A double blind crossover trial was performed with placebo and cholestyramine enterocoated with cellulose acetate phthalate. During treatment with cholestyramine the daily faecal output decreased, the number of defecations each week decreased, and the intestinal transit time increased. Acceptability of the tablets was high, in contrast with general clinical experience with cholestyramine powder. No change was observed in the total faecal output of bile acids or fat.

Cholestyramine tablets caused a reduction in diarrhoea without noticeably interfering with the metabolism of fat or bile acid.

Department of Gastroenterology P, Rigshopitalet, University of Copenhagen, Denmark

OLI JACOBSEN, MD, registrar

MARGRETHE THALE, MSC, biochemist

STIG JARNUM, MD, chief physician and senior lecturer

Division of Gastroenterology, Department of Internal Medicine,

Hvidovre Hospital, University of Copenhagen, Denmark

LISELOTTE HØJGAARD, MD, registrar

ELLINOR HYLANDER MØLLER, MD, senior registrar and lecturer

EINAR KRAG, MD, chief physician and senior lecturer

Central Hospital Pharmacy, Herlev

TORBEN O WIELANDT, MD, pharmacist

Correspondence to: Dr Liselotte Hoigaard, Department of Clinical Physiology and Nuclear Medicine 239, Hvidovre Hospital, DK-2650 Copenhagen.

\section{Introduction}

Some bile acids are absorbed passively in the proximal small intestine, but there is also an important active transport mechanism in the terminal ileum. ${ }^{\prime}$ : Patients with an ileal resection of $30 \mathrm{~cm}$ or more may develop malabsorption of bile acid, resulting in an increased passage of bile acids into the colon, where dihydroxy bile acid induces the secretion of salt and water and hence diarrhoea. ${ }^{3}$ Hitherto, conventional cholestyramine powder has been used with some success to sequester bile acid,': But such treatment has two physiological disadvantages. Firstly, the jejunal concentration of non-sequestered bile acids is below the optimum for sufficient solubilisation of the lipolytic products after meals and thus the result is malabsorption of fat, steatorrhoea, and diarrhoea induced by fatty acids. Secondly, malabsorption of bile acid is increased because sequestered bile acids are not available for small intestinal absorption. It might therefore be an advantage to ingest cholestyramine in a tablet that releases the active substance in the colon, thereby not influencing malabsorption of bile acid and fat. In vivo studies of patients who had not had operations and healthy volunteers suggested that cellulose acetate phthalate might be an ideal coating for cholestyramine tablets as the coating, and hence the tablet, disintegrated in the most distal part of the ileum, caecum, or ascending colon.

The aim of our study was to investigate the effect of cholestyramine tablets coated with cellulose acetate phthalate in patients with diarrhoea and malabsorption of bile acid caused by ileal resection.

\section{Patients and methods}

Eleven women and three men aged 27-66 (median 42) consented, in accordance with the Helsinki II declaration, to participate in the study, which was accepted by the local human studies committee. The patients had undergone ileal resection of $40-150 \mathrm{~cm}$ (median 65 $\mathrm{cm}$ ) because of Crohn's disease, but at least half of the colon had been preserved. The table gives clinical and laboratory data. The chronic inflammatory bowel disease was mild in all patients and did not change during the study. Five patients received sulphasalazine $3 \mathrm{~g}$ daily and two prednisone $2 \cdot 5-7 \cdot 5 \mathrm{mg}$ daily.

The study lasted three weeks: one week of treatment with cholestyramine tablets coated with cellulose acetate phthalate; one week of equilibrium (washout period); and one week of treatment with placebo tablets containing barium sulphate coated with cellulose acetate 